https://www.journal-imab-bg.org

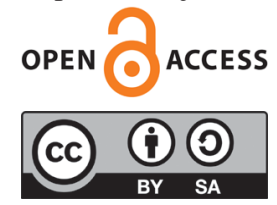

Review article

\title{
REVIEW ON ELECTROENCEPHALOGRAPHIC FINDINGS IN PATIENTS WITH ALZHEIMER'S DIS- EASE
}

\author{
Ivan Todorov, Kosta Kostov \\ Neurology Clinic, Medical Institute - Ministry of Interior, Sofia, Bulgaria.
}

\begin{abstract}
SUMMARY:
Nowadays, with the constant enhancement of the longevity of the human population, the spreading of dementia is in steady rising. Among the many different sources of progressive cognitive impairment, Alzheimer's disease plays a major role being the most common reason for mental decline in the elderly population. Alzheimer's disease is a neurodegenerative disease of the central nervous system that leads to progressive cognitive impairment and has severe health, social and economic tolls. The lack of effective treatment and the problems of the daily living that the disease creates for the patients and their families raises many important issues in modern times. Due to the effect on the individuals and the need for a permanent caregiver, it is of high importance to have accessible tools for early diagnostic and assessment of the ongoing treatment. Electroencephalography is a noninvasive, easily reproductive diagnostic method with low cost that can be performed in different stages of the diseases of the central nervous system and give input on the current condition. This review presents the current achievements in the field of the usage of electroencephalography and its specific findings in patients with Alzheimer's disease and the qualitative and quantitative changes that appears and are important for early diagnosis, differential diagnostic, prediction of acceleration of the pathological process, distinguishing of co-existing conditions and follow-up of the effect of the administered treatment.
\end{abstract}

Keywords: Alzheimer's disease, electroencephalography, qualitative and quantitative changes, review,

\section{BACKGROUND:}

Electroencephalography (EEG) is an electrophysiological method for studying the functional bioelectric activity of the brain. This is a noninvasive method, where electrodes are placed at specific positions on the scalp in a predetermined order to detect neural bioelectrical oscillations. The potentials generated in the underlying cortex are the source of EEG registered with surface electrodes. The superficial EEG directly reflects mainly potential local changes, but it can also reveal abnormalities in remote locations. These abnormalities lead to changes in cortical potential and present themselves as patterns of similar duration and amplitude in vast areas of the brain. They are called "projection" or "bilateral synchrony". Although these rhythms can be induced by distant regions, they are generated in the cortex, below the recording electrodes.

In the last 25 years, digital EEG technologies and quantitative EEG (qEEG) methods have become popular. The main prerequisites for their introduction, on the one hand, are the possibilities for paperless recording, reformatting of the installation, changing of filters and other parameters of the EEG recording after its registration, and on the other - the disadvantages of routine EEG for quantifying some variables, recording and processing large volumes of data, especially when monitoring patients in operation theaters and intensive units, making measurements that depict accurate time relationships between events across multiple channels, statistical analyzes, and also an easily accessible presentation of the results. To the classical EEG, methodology is added new possibilities for quantitative EEG analysis, allowing the reproduction of topography with a mapping of electrical brain activity, enhancing the informative and scientific value of the study. The EEG finding is used to assist in the diagnostic process of different neurological diseases.

Alzheimer's disease is a degenerative disease of the central nervous system, clinically characterized by progressive dementia and is the most common cause of dementia in the general population.

Alzheimer's disease begins with biological changes in the brain, with no accompanying cognitive impairment - an asymptomatic phase, later going into a phase with memory abnormalities with specific abnormal biomarkers and subsequently to a phase with developed symptoms of varying degrees. The average life expectancy of patients with Alzheimer's disease is about 10-12 years after diagnosis and goes through three major stages - mild, moderate and severe. The first is the stage of amnesia, typically 1 to 3 years in duration, with impaired episodic memory for near-term events and mild disorders in other cognitive functions and presence of depression and anxiety. The second stage is a moderate or demented stage with a normal duration of 1 to 7 years, characterized by significant cognitive decline, with the patient becoming more dependent on others to the extent that he or she is unable to live independently and has behavioral disor- 
ders such as agitation, confusion and delusions occur. The third stage, called vegetative, usually lasts from 1 to 3 years and is characterized by complete dependence of the patient on foreign help and care.

\section{REVIEW RESULTS:}

Determining the diagnosis in patients with moderate intellectual deficiency or in the early stages of dementia may be aided by noninvasive functional tests that may confirm the clinical suspicion. Neuroimaging methods are at the center of such a study, but unfortunately, their high cost limits their daily clinical use [1].

In the study of patients with dementia via standard EEG, the presence of focal or generalized slow background activity may be associated with certain changes or, with the exception of the decrease in beta band activity, such changes may also be associated with normal aging processes. Quantitative EEG methods show similar results to those detected by routine EEG, but sometimes frequency EEG analysis allows a more accurate measurement of the activity slowdown available than just the routine EEG. EEG sensitivity, with or without quantitative analysis, is high for moderate and severe dementia, and the degree of qEEG or routine EEG abnormalities is consistent with the degree of dementia and disease progression [2, 3, 4, 5].

The use of qEEG in mild cognitive impairment in the early stages of the disease is particularly appropriate, and brain dysfunction detected in these temporo-parietal areas in patients with clinical data for dementia shows an analogy with the results of neuroimaging studies and may serve as a predictor of prognosis [6].

Relatively high specificity and sensitivity has been found in the use of qEEG tests to differentiate patients with dementia and age-related changes or depression. It should be noted immediately that sometimes EEG frequency analysis may not assist in the differential diagnosis of different types of dementia as opposed to routine EEG, whereby some specific wave patterns occurring at a higher frequency in certain encephalopathies and dementia conditions, can determine the clinical diagnosis. The clinical role of electrophysiological studies is limited in patients in whom the possibility of dementia remains an uncertain problem after taking of anamnestic data, somatic and neurological status, neuroimaging tests and blood tests appropriate for the diagnosis of the disease [7].

EEG recording activities such as polymorphic slow waves in theta or delta range, frontal intermittent rhythmic delta activity (FIRDA), and other EEG changes in Alzheimer's patients are not specific, and any quantification of this activity was not possible several years ago. New techniques have been found to overcome these problems, and nowadays the hallmarks of EEG abnormalities in patients with Alzheimer's disease are the following: shifting the energy spectrum to lower frequencies, reducing the coherence of fast rhythms and changes in the characteristics of EEG, which can be found at an early stage in a wide frequency range [8]. These abnormalities are considered to be associated with functional disconnections between cortical areas leading to the death of cortical neurons, axonal pathology and cholinergic deficits $[9,10,11]$.

The EEG has a high sensitivity in separating Alzheimer's patients from normal control groups and may exclude other pathologies. This is the reason why some clinicians suggest that all patients with Alzheimer's disease should undergo EEG at least once, as well as MRI [12, 13]. On the other hand, the incidence of correctly identified cases of the electrophysiological disease varies widely between $29 \%$ and $42 \%$ in the initial stages and between $60 \%$ and $80 \%$ in the later stages [14]. But a new feature, EEG spectrotemporal modulation of energy, can provide an automatic diagnosis of Alzheimer's disease with over $91 \%$ accuracy [15]. In the later stages of the disease, unusual discoveries such as slow waves are very common. The normal EEG in these patients raises questions about the diagnosis of Alzheimer's disease, making a diagnosis of subcortical dementia or degeneration of the frontal lobå more possible. In addition, EEG may detect epileptic activity, a serious prognostic factor for the future development of the disease. At a younger age, greater cognitive decline and history of antipsychotic medication use are considered independent risk factors for seizures in patients with Alzheimer's disease [16].

Standard EEG visual analyzes in patients with Alzheimer's disease are characterized by an increase in widespread delta and theta activity, as well as a decrease in posterior alpha and beta activity. As mentioned earlier, these features appear only in the later stages of the disease [17].

Electronic EEG spectral analysis (qEEG) in patients with Alzheimer's disease provides more quantitative data than visual analysis. QEEG also showed an increase in delta and theta power and a parallel decrease in alpha and beta activity compared to adult controls. To be more precise, the amount of relative theta band increases and that of the fast alpha band decreases. There is also an impaired functional link between frontoparietal and frontotemporal regions in the alpha and beta bands [18]. The global connectivity of neural circuits and the dimension of global correlation, which are both measures of functional connectivity, differ within certain bands, which indicate reduced functional connectivity in the alpha and theta bands [10].

According to recent research data, EEG markers allow the correct determination of Alzheimer's disease in up to $88.3 \%$ [19]. According to recent data, abnormal electroencephalographic rhythms are also sensitive to the progression of the early stage of the disease within one year. In this case, EEG sources may represent cost-effective and noninvasive markers with which to identify patients with the disease that are expected to worsen more rapidly [20]. Researchers are trying to relate EEG changes not only to the general deterioration of the patient but also to the specific aspects that result from this decline. An interesting example of the above is the attempt at using qEEG characteristics as prognostic markers in Alzheimer's disease. In a study of 31 patients with the disease, 
disorders of daily activities and death were associated with changes in right delta relative activity, whereas the onset of incontinence was associated with relative theta activity [21]. Finding this population can help us make an early diagnosis and intervention.

There is a correlation between the degree of EEG anomaly and cognitive impairment [17]. Recent scientific evidence shows correlations between EEG delta and alpha activity in the left temporo-parietal cortex and MMSE scores. These results support the hypothesis of asymmetric progression of Alzheimer's disease [22]. Some authors acknowledge that MMSE results are strongly related to the magnitude of spectral power in theta and alpha bands in the back of the neural network of the brain [18].

Some researchers in one article comparing magnetic resonance imaging data, cognitive tests and EEG recording found that the better the result of cognitive tests, the greater the volume of gray matter and alpha activity and the lower the pathological delta activity [23]. eLORETA correlation analysis showed that delayed synchronization in the theta band had a negative correlation with MMSE scores, meaning that the greater cognitive decline represented by the low MMSE score came with higher activity in the theta band. This involves impaired functional connectivity of specific cortical areas, such as left temporal and right prefrontal and left anterior temporal and right central cortex. Significant correlations of theta activity with MMSE scores have also been observed between the left temporal area and the midbrain and the right temporal and inferior parietal cortex [24].

In addition, the combination of EEG data, neuropsychological assessment and cardiovascular history increase the accuracy of diagnosing dementia and mild cognitive deficits from $80 \%$ to $92 \%$. The same method is able to identify the following subgroups with relative accuracy: Alzheimer's disease $(92 \%, 12 / 13)$, vascular dementia $(73 \%, 8 / 11)$, mixed dementia $(100 \%, 4 / 4)$ and mild cognitive deficits $(80 \%, 4 / 5)$ [25]. Independent use of EEG contributes even more than clinical symptoms and neuropsychology to differential diagnosis with some other dementias. Changes in the frequency of activity may reflect cortical or subcortical pathology [26]. In addition, in patients with mild cognitive deficits and Alzheimer's disease, the delta and alpha rhythms in the posterior EEG outflows appear to be more sensitive to Alzheimer's disease and associated neurodegenerative processes and cognitive status than to accompanying lesions to subcortical areas [27]. A review of the usefulness of EEG in the diagnosis of dementia also suggests that EEG may be useful in addition to the diagnosis of Dementia with Levi's body and Alzheimer's disease [28]. Total EEG activity and frontal intermittent rhythmic delta activity (FIRDA) may be useful in the differential diagnosis between Dementia with Levi's body and Alzheimer's disease with good sensitiv- ity and specificity [29]. EEG is usually normal in frontotemporal dementia, and focal changes can be seen in advanced vascular dementias [28], especially if vascular lesions are enlarged [30]. Selected qEEG parameters could be used in addition to the differential diagnosis between Alzheimer's disease and subcortical vascular dementia [31].

Increased EEG slow-wave activity in patients with Alzheimer's disease may reflect cholinergic deficiency. Some authors only one week after initiation of rivastigmine, noticed that theta activity was significantly reduced. According to this study, treatment responders had a greater reduction in theta activity after one week of therapy and better short-term memory compared to baseline than non-responders. These data suggest that EEG can not only detect the therapeutic effect of drugs but also be used in combination with a neuropsychological assessment to predict the response of rivastigmine in patients with Alzheimer's disease [32]. Other authors have studied patients with Alzheimer's disease before treatment with donepezil and found that posterior sources of delta and alpha frequencies were greater in amplitude in non-responders. A year later, after initiation of treatment, a reduction in the activity reduction of both occipital and temporal alpha sources characterizes treatment responders. These results suggest that responders and non-responders have different cortical EEG rhythms [33]. It was found that after a three-month period of administration of rivastigmine, spectral analysis of EEG data showed a significant decrease in delta and theta bandwidths in the frontal, parietal, and temporal regions [34]. A previous study on the effect of donepezil finished with the observation that the metabolic activation of cholinesterase inhibitors may particularly affect the posterior parietal area, which is often affected by hypoperfusion in Alzheimer's disease [35]. QEEG may be a useful method for measuring response to Alzheimer's therapies. It may also monitor the treatment of Alzheimer's disease by reflecting the doserelated treatment [36].

\section{CONCLUSION:}

The EEG method has been demonstrated as a reliable diagnostic tool in dementia studies [9, 37, 38]. Alzheimer's disease is cortical dementia, in which anomalies of EEG rhythms are more frequently manifested, while in subcortical dementia, relatively normal EEG patterns are shown. EEG analysis in Alzheimer's disease also allows for noninvasive assessment of synaptic dysfunction. EEG abnormalities reflect the anatomical and functional defects of the cerebral cortex that develop during the course of the disease. The use of EEG with modern statistical methods seems to be a reliable method for classifying clinical cases of cognitive impairment as well as the effectiveness of treatment and prognosis [39, 40]. 


\section{REFERENCES:}

1. Minchev D. (Editor). [Basic of clinical electroencephalography.] [in Bulgarian] Zograf, Varna, 2008: 186211.

2. Kuusisto J, Koivisto K, Kervinen K, Mykkanen L, Helkala EL, Vanhanen M, et al. Association of apolipoprotein $\mathrm{E}$ phenotypes with late onset Alzheimer's disease: population based study. BMJ. 1994 Sep 10; 309(6955):636-8. [PubMed]

3. Hier DB, Mangone CA, Ganellen R, Warach JD, Van Egeren R, Perlik SJ, et al. Quantitative Measurement of Delta Activity in Alzheimer's Disease. Clin Electroencephalogr. $1991 \mathrm{Jul}$; 22(3):178-82. [PubMed]

4. Prichep LS, John ER, Ferris SH, Reisberg B, Almas M, Alper K, et al. Quantitative EEG correlates of cognitive deterioration in the elderly. Neurobiol Aging. 1994 Jan-Feb; 15(1):85-90. [PubMed]

5. Yener GG, Leuchter AF, Jenden D, Read SL, Cummings JL, Miller BL. Quantitative EEG in Frontotemporal Dementia. Clin Electroencephalogr. 1996 Apr;27(2):61-8. [PubMed]

6. Claus JJ, Kwa VI, Teunisse S, Walstra GJ, van Gool WA, Koelman JH, et al. Slowing on quantitative spectral EEG is a marker for rate of subsequent cognitive and functional decline in early Alzheimer disease. Alzheimer Dis Assoc Disord. 1998 Sep;12(3):167-74. [PubMed]

7. Deslandes A, Veiga H, Cagy M, Fiszman A, Piedade R, Ribeiro P. Quantitative electroencephalography (qEEG) to discriminate primary degenerative dementia from major depressive disorder (depression). Arq Neuropsiquiatr. 2004 Mar; 62(1):44-50. [PubMed]

8. Tsolaki A, Kazis D, Kompatsiaris I, Kosmidou V, Tsolaki M. Electroencephalogram and Alzheimer's Disease: Clinical and Research Approaches. Int J Alzheimers Dis. 2014;2014:349249. [PubMed]

9. Jeong J. EEG dynamics in patients with Alzheimer's disease. Clin Neurophysiol. 2004 Jul;115(7):1490505. [PubMed]

10. Jelles B, Scheltens P, van der Flier WM, Jonkman EJ, Lopes da Silva FH, Stam CJ. Global dynamical analy- sis of the EEG in Alzheimer's disease: frequency-specific changes of functional interactions. Clin Neurophysiol. 2008 Apr;119(4):837-41. [PubMed]

11. Czigler B, Csikos D, Hidasi Z, Anna Gaal Z, Csibri E, Kiss E, et al. Quantitative EEG in early Alzheimer's disease patients-power spectrum and complexity features. Int J Psychophysiol. 2008; 68(1):75-80. [PubMed]

12. Jonkman EJ. The role of the electroencephalogram in the diagnosis of dementia of the Alzheimer type: an attempt at technology assessment. Neurophysiol Clin. 1997;27(3):211219. [PubMed]

13. Hegerl U, Moller HJ. Electroencephalography as a diagnostic instrument in Alzheimer's disease: reviews and perspectives. Int Psychogeriatr. 1997; 9(1):237-252. [PubMed]

14. Stam CJ, Jelles B, Achtereekte HAM, van Birgelen JH, Slaets JPJ. Diagnostic Usefulness of Linear and Nonlinear Quantitative EEG Analysis in Alzheimer's Disease. Clin Electroencephalogr. 1996 Apr; 27(2):69-77. [PubMed]

15. Trambaiolli LR, Falk TH, Fraga FJ, Anghinah R, Lorena AC. EEG spectro-temporal modulation energy: A new feature for automated diagnosis of Alzheimer's disease. Annu Int Conf IEEE Eng Med Biol Soc, Boston, MA. 2011;1:3828-3831. [PubMed]

16. Irizarry $\mathrm{MC}$, Jin $\mathrm{S}, \mathrm{He} \mathrm{F}$, Emond JA, Raman R, Thomas RG, et al. Incidence of New-Onset Seizures in Mild to Moderate Alzheimer Disease. Arch Neurol. 2012; 69(3):368-372. [PubMed]

17. Brenner RP, Reynolds III CF, Ulrich RF. Diagnostic efficacy of computerized spectral versus visual EEG analysis in elderly normal, demented and depressed subjects. Electroencephalogr Clin Neurophysiol. 1988; 69(2):110-117. [PubMed]

18. Hsiao FJ, Wang YJ, Yan SH, Chen WT, Lin YY. Altered oscillation and synchronization of default-mode network activity in mild Alzheimer's disease compared to mild cognitive impairment: an electrophysiological study. PLoS One. 2013 Jul 11;8(7): e68792. [PubMed]

19. Moretti DV, Frisoni GB,
Fracassi C, Pievani M, Geroldi C, Binetti G, et al. MCI patients' EEGs show group differences between those who progress and those who do not progress to AD. Neurobiol Aging. 2011; 32(4):563-571. [PubMed]

20. Babiloni C, Lizio R, Del Percio C, Marzano N, Soricelli A, Salvatore E, et al. Cortical sources of resting state EEG rhythms are sensitive to the progression of early stage Alzheimer's disease. J Alzheimers Dis. 2013; 34(4): 1015-1035. [PubMed]

21. Rodriguez G, Nobili F, Arrigo A, Priano F, De Carli F, Francione S, et al. Prognostic significance of quantitative electroencephalography in Alzheimer patients: preliminary observations. Electroencephalogr Clin Neurophysiol. 1996;99(2):123-128. [PubMed]

22. Gianotti LRR, Kunig G, Lehmann D, Faber PL, Pascual-Marqui RD, Kochi K, et al. Correlation between disease severity and brain electric LORETA tomography in Alzheimer's disease. Clin Neurophysiol. 2007; 118(1):186-196. [PubMed]

23. Babiloni C, Carducci F, Lizio R, Vecchio F, Baglieri A, Bernardini S, et al. Resting state cortical electroencephalographic rhythms are related to gray matter volume in subjects with mild cognitive impairment and Alzheimer's disease. Hum Brain Mapp. 2013; 34(6):1427-1446. [PubMed]

24. Canuet L, Tellado I, Couceiro V, Fraile C, Fernandez-Novoa L, Ishii R, et al. Resting-state network disruption and APOE genotype in Alzheimer's disease: a lagged functional connectivity study. PLoS One. 2012; 7(9): e46289. [PubMed]

25. Snyder SM, Hall JR, Cornwell SL, Falk JD. Addition of EEG improves accuracy of a logistic model that uses neuropsychological and cardiovascular factors to identify dementia and MCI. Psychiatry Res. 2011; 186(1):97-102. [PubMed]

26. Gasser US, Rousson V, Hentschel F, Sattel H, Gasser T. Alzheimer disease versus mixed dementias: an EEG perspective. Clin Neurophysiol. 2008; 119(10):22552259. [PubMed]

27. Babiloni C, Lizio R, Carducci 
F, Vecchio F, Redolfi A, Marino S, et al. Resting state cortical electroencephalographic rhythms and white matter vascular lesions in subjects with alzheimer's disease: an Italian multicenter study. J Alzheimers Dis. 2011; 26(2):331-346. [PubMed]

28. Micanovic C, Pal S. The diagnostic utility of EEG in early-onset dementia: a systematic review of the literature with narrative analysis. $\mathrm{J} \mathrm{Neu}$ ral Transm. 2014; 121(1):59-69. [PubMed]

29. Roks G, Korf ESC, van der Flier WM, Scheltens P, Stam CJ. The use of EEG in the diagnosis of dementia with Lewy bodies. J Neurol Neurosurg Psychiatry. 2008; 79(4): 377-380. [PubMed]

30. Van Straaten ECW, de Haan W, de Waal H, Scheltens P, van der Flier WM, Barkhof F, et al. Disturbed oscillatory brain dynamics in subcortical ischemic vascular dementia. $B M C$ Neurosci. 2012; 13:85. [PubMed]

31. Gawel M, Zalewska E, Szmidt$\mathrm{Sa}^{3}$ kowska E, Kowalski J. The value of quantitative EEG in differential diagnosis of Alzheimer's disease and subcortical vascular dementia. J Neurol Sci. 2009 Aug 15;283(1-2):127-33. [PubMed]
32. Adler G, Brassen S, Chwalek K, Dieter B, Teufel M. Prediction of treatment response to rivastigmine in Alzheimer's dementia. J Neurol Neurosurg Psychiatry. 2004; 75(2): 292-294. [PubMed]

33. Babiloni C, Cassetta E, Dal Forno G, Del Percio C, Ferreri F, Ferrie $\mathrm{R}$, et al. Donepezil effects on sources of cortical rhythms in mild Alzheimer's disease: Responders vs. Non-Responders. Neuro Image. 2006; 31(4): 1650-1665. [PubMed]

34. Gianotti LRR, Kunig G, Faber PL, Lehmann D, Pascual-Marqui RD, Kochi K, et al. Rivastigmine effects on EEG spectra and three-dimensional LORETA functional imaging in Alzheimer's disease. Psychopharmacology. 2008; 198(3):323-332. [PubMed]

35. Rodriguez G, Vitali P, Canfora M, Calvini P, Girtler N, De Leo C, et al. Quantitative EEG and perfusional single photon emission computed tomography correlation during longterm donepezil therapy in Alzheimer's disease. Clin Neurophysiol. 2004; 115(1):39-49. [PubMed]

36. Sneddon R, Shankle WR, Hara J, Rodriquez A, Hoffman D, Saha U. QEEG Monitoring of Alzheimer's Dis- ease Treatment: A Preliminary Report of Three Case Studies. Clin EEG and Neurosci. 2006 Jan;37(1):54-59. [PubMed]

37. Lizio R, Vecchio F, Frisoni GB, Ferri R, Rodriguez G, Babiloni C. Electroencephalographic rhythms in Alzheimer's disease. Int J Alzheimers Dis. 2011; 2011(927573):11. [PubMed]

38. Rossini PM, Rossi S, Babiloni C, Polich J. Clinical neurophysiology of aging brain: from normal aging to neurodegeneration. Prog Neurobiol. 2007; 83(6):375-400. [PubMed]

39. Snaedal J, Johannesson GH, Gudmundsson TE, Blin NP, Emilsdottir AL, Einarsson B, et al. Diagnostic accuracy of statistical pattern recognition of electroencephalogram registration in evaluation of cognitive impairment and dementia. Dement Geriatr Cogn Disord. 2012;34(1):5160. [PubMed]

40. Babiloni C, Del Percio C, Bordet R, Bourriez JL, Bentivoglio M, Payoux P, et al. Effects of acetylcholinesterase inhibitors and memantine on resting-state electroencephalographic rhythms in Alzheimer's disease patients. Clin Neurophysiol. 2013 May;124(5):837-50. [PubMed]

Please cite this article as: Todorov I, Kostov K. Review on electroencephalographic findings in patients with Alzheimer's disease. J of IMAB. 2021 Jan-Mar;27(1):3529-3533. DOI: https://doi.org/10.5272/jimab.2021271.3529

Address for correspondence: Ivan Todorov

Neurology clinic, Medical Institute-Ministry of Interior, 79, Skobelev Blvd., 1606 Sofia, Bulgaria E-mail: ivan__todorov@abv.bg 